\title{
Efficacy of thrombomodulin for acute exacerbation of idiopathic pulmonary fibrosis and nonspecific interstitial pneumonia: a nonrandomized prospective study
}

\author{
This article was published in the following Dove Press journal: \\ Drug Design, Development and Therapy \\ 23 October 2015 \\ Number of times this article has been viewed
}

Mitsuhiro Abe

Kenji Tsushima

Takuma Matsumura

Tsukasa Ishiwata

Yasunori Ichimura

Jun Ikari

Jiro Terada

Yuji Tada

Seiichirou Sakao

Nobuhiro Tanabe

Koichiro Tatsumi

Department of Respirology, Graduate School of Medicine, Chiba University, Chiba, Japan
Correspondence: Kenji Tsushima Department of Respirology, Graduate School of Medicine, Chiba University, I-8-I Inohana, Chuo-ku, Chiba 260-8670, Japan

Tel +8I 432262576

Email tsushimakenji@yahoo.co.jp
Purpose: Acute exacerbation (AE) is an important outcome of idiopathic pulmonary fibrosis (IPF) and nonspecific interstitial pneumonia (NSIP). Recombinant human soluble thrombomodulin (rhTM) is a new drug for the treatment of disseminated intravascular coagulation in Japan. The objective of this study was to evaluate the efficacy of rhTM for AE of IPF/NSIP.

Methods: Twenty-two patients with AE-idiopathic interstitial pneumonia (16 patients with IPF and six patients with NSIP) were enrolled in our study. Among them, eleven patients were treated with rhTM (rhTM group), and eleven patients were treated without rhTM (non-rhTM group). Patients admitted to our hospital prior to December 2013 were treated with rhTM, while those admitted after January 2014 were treated without rhTM. The primary endpoint was mortality at 90 days after AE treatment. The secondary endpoint was the safety of rhTM for AE-IPF/ AE-NSIP. In addition, we examined prognostic factors of AE-IPF/AE-NSIP.

Results: The mortality rate was significantly lower in the rhTM group than in the non-rhTM group (mortality rate at 90 days: $36 \%$ vs $90 \%, P=0.023$; median survival time: not reached vs 15.0 days, $P=0.019$ ). A univariate analysis revealed the respiratory rate (hazard ratio [HR] 1.09, $95 \%$ confidence interval $[\mathrm{CI}] 1.00-1.18, P=0.039)$ and rhTM administration (HR $0.21,95 \% \mathrm{CI}$ $0.06-0.77, P=0.013$ ) as predictors of mortality at 90 days, and a multivariate analysis identified rhTM administration (HR $0.025,95 \%$ CI $0.0006-0.94, P=0.046$ ) as an independent predictor of mortality at 90 days. No serious adverse events were observed.

Conclusion: The administration of rhTM is associated with reductions in mortality in patients with AE-IPF/NSIP, without causing adverse events.

Keywords: recombinant human soluble thrombomoduline, acute exacerbation, idiopathic pulmonary fibrosis, nonspecific interstitial pneumonia

\section{Introduction}

Acute exacerbation (AE) was first described in patients with idiopathic pulmonary fibrosis (IPF). ${ }^{1} \mathrm{AE}$ is an important complication in patients with IPF. The incidence rate of AE-IPF at 1 year is $14.2 \%,{ }^{2}$ and the outcomes of AE-IPF are very poor, with reported mortality rates at 1 month and 3 months of $\sim 60 \%$ and $\sim 67 \%$, respectively. ${ }^{3}$ Patients with nonspecific interstitial pneumonia (NSIP) have also been reported to develop AE, and the incidence rate of AE-NSIP at 1 year is $4.2 \% .{ }^{4}$ Usui et al reported that, in their retrospective analysis, the survival rate of AE among patients with chronic fibrosing interstitial pneumonia (including IPF, NSIP, and chronic hypersensitivity pneumonia) was $67 \%$ at 30 days, $43 \%$ at 60 days, and $40 \%$ at 90 days in 51 patients. 5 In general, high-dose corticosteroid therapy is often administered to patients with 
AE-IPF, although there is currently insufficient evidence regarding the usefulness of corticosteroid treatment in these cases. Furthermore, while some authors have reported the efficacy of immunosuppressive agents (ie, cyclosporine A), ${ }^{6-8}$ there is no evidence to support this observation at present.

Recombinant human soluble thrombomodulin (rhTM) (Recomodulin ${ }^{\circledR}$; Asahi Kasei Pharma Corporation, Tokyo, Japan) is a transmembrane protein expressed on the endothelial cell surface, which plays an important role in the regulation of intravascular coagulation. ${ }^{9}$ In Japan, rhTM has been approved for the treatment of disseminated intravascular coagulation (DIC). Thrombomodulin has an anticoagulation and an anti-inflammatory effect, ${ }^{9,10}$ and Ogawa et al reported that, in 86 patients with sepsis-induced DIC who required mechanical ventilator management, rhTM administration had a significant beneficial effect on both mortality and respiratory dysfunction. ${ }^{11}$ Recently, there have been trials of the administration of rhTM in patients with AE-IPF/NSIP; however, the efficacy of this drug remains unclear. Therefore, the purpose of this study was to prospectively compare and analyze clinical data for patients with AE-IPF/NSIP in order to evaluate the efficacy of rhTM in this population.

\section{Materials and methods}

This study was a single-center prospective study. The research protocol was approved by the Human Ethics Committee of Chiba University Hospital, and informed consent was obtained from all patients and their family members. The trial registration number is UMIN000012590.

\section{Patients}

Between October 2012 and August 2014, 46 patients suspected of having an AE of interstitial pneumonia were treated at Chiba University Hospital (Figure 1). Five patients with collagen vasculitis syndrome-related IP, three patients with drug-induced IP, three patients with eosinophilic pneumonia, three patients with acute interstitial pneumonia, one patient with radiation pneumonia, and one patient with hypersensitivity pneumonia were excluded. Four patients with complications related to lower respiratory pneumonia and four patients diagnosed with DIC on admission were excluded. The Japanese Association for Acute Medicine DIC scoring system was used to identify DIC in patients. ${ }^{12}$

\section{Diagnosis of IPF and NSIP}

The diagnosis of IPF was made according to the 2011 ATS/ERS/JRS/ALAT guidelines. ${ }^{13}$ The high-resolution computed tomography (HRCT) features of NSIP include the following: 1) bilateral ground-glass areas in the lungs, sometimes with an extensive distribution; 2) reticular opacity, which may be superimposed on a ground-glass pattern; and 3) traction bronchiectasis, which may be parallel in course through the lungs or extremely irregular. ${ }^{14}$ Enrolled patients clinically diagnosed with connective tissue disease were excluded.

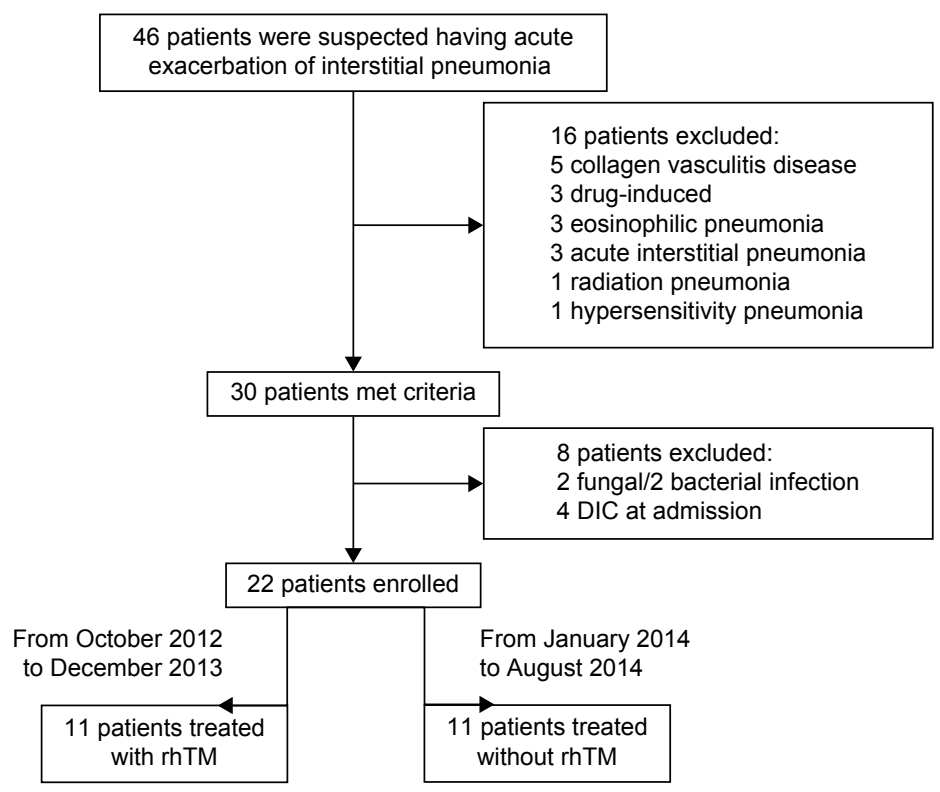

Figure I Flow diagram of patients with acute exacerbation.

Abbreviations: DIC, disseminated intravascular coagulation; rhTM, recombinant human thrombomoduline. 


\section{Diagnosis of $\mathrm{AE}$}

The diagnosis of AE was based on the criteria proposed by Kondoh et al. ${ }^{1}$ These criteria contain four conditions: 1) onset of exacerbation of dyspnea within a few weeks, 2) newly developing diffuse pulmonary infiltrates on chest X-ray films, 3) $>10 \mathrm{mmHg}$ decreases in oxygen partial pressure $\left(\mathrm{PaO}_{2}\right)$ in the resting arterial blood compared to the previous measurements, and 4) the absence of an apparent infectious agent. Collard et al suggested that the findings of HRCT comprise new bilateral ground-glass abnormalities and/or consolidation superimposed on a background reticular or honeycomb pattern, consistent with the usual interstitial pneumonia pattern. ${ }^{15}$

In order to exclude cases of infection, we examined sputum and/or bronchoalveolar lavage (BAL) cultures in all cases. In addition, we examined the levels of urinary antigens for Streptococcus pneumonia and Legionella pneumophilia serotype 1, antigens for influenza A and B viruses using pharyngeal swabs, antigenemia for cytomegalovirus, and serum antigens for Aspergillus. Moreover, we excluded other alternative etiologies, including left heart failure, pulmonary embolism, and identifiable causes of acute lung injury. ${ }^{15}$

\section{Laboratory data}

The following parameters were measured on the first day of admission (day 1) and days 3 and 8 after admission: white blood cell (WBC) count and the levels of fibrinogen degradation products (FDP, normal range: $<5 \mathrm{mg} / \mathrm{mL}$ ), D-dimer (normal range: $<1 \mathrm{ng} / \mathrm{mL}$ ), thrombin-antithrombin complex (normal range: $<4 \mathrm{ng} / \mathrm{mL}$ ), plasmin-alpha 2-plasmin inhibitor complex (normal range: $<0.8 \mathrm{mg} / \mathrm{mL}$ ), C-reactive protein (CRP, normal range: $<0.3 \mathrm{mg} / \mathrm{dL}$ ), serum lactate dehydrogenase (LDH, normal range: 120-235 IU/L), brain natriuretic peptide (normal range: $20 \mathrm{pg} / \mathrm{mL}$ ), Krebs von den Lungen-6 (KL-6, normal range: $<500 \mathrm{U} / \mathrm{L}$ ), and surfactant protein-D (normal range: $<110 \mathrm{ng} / \mathrm{mL}$ ).

\section{Treatment strategy for AE-idiopathic interstitial pneumonia}

The treatment strategy was determined before the start of the study as follows. The patients with AE-IPF/NSIP enrolled between October 2012 and December 2013 were administered rhTM (rhTM group), and the patients with AE-IPF/NSIP enrolled between January 2014 and December 2014 were not administered rhTM (non-rhTM group). The patients were treated with methylprednisolone pulse therapy (intravenous administration of $1 \mathrm{~g}$ of methylprednisolone for 3 days) and maintenance therapy with corticosteroids. We recommended immunosuppressive agents (ie, cyclophosphamide and/or cyclosporine) to be administered in patients with AE-IPF/NSIP, except for the super-elderly ( $>81$ years) individuals with a poor general condition and individuals who demonstrated a significant improvement with the initial treatment.

In the rhTM group, $0.06 \mathrm{mg} / \mathrm{kg} / \mathrm{d}$ of rhTM (diluted in $100 \mathrm{~mL}$ of sterile saline) was administered intravenously for 30 minutes over the first 6 days. ${ }^{11}$

Oxygen therapy was administered to keep the $\mathrm{PaO}_{2}$ value $>60 \mathrm{mmHg}$ (corresponding to a $\mathrm{SpO}_{2}$ of $90 \%$ ). We first chose nonpositive pressure ventilation therapy. If the $\mathrm{PaO}_{2}$ value was not maintained $>60 \mathrm{mmHg}$, the patient was treated with noninvasive positive pressure ventilation or high-flow nasal oxygen therapy. Whether invasive mechanical ventilation was performed was determined by respecting the intentions of the patient and his/her family members.

\section{Endpoints}

The primary endpoint was mortality at 90 days after treatment for AE-IPF/NSIP. The secondary endpoint was the safety of rhTM in patients with AE-IPF/NSIP.

\section{Statistical analysis}

The clinical data are expressed as the mean $\pm \mathrm{SD}$. We compared the two groups using the Mann-Whitney $U$-test for continuous variables and using the Fisher's exact test for categorical variables. A Kaplan-Meier model was generated to evaluate survival rate. Univariate and multivariate analyses were performed based on Cox regression modeling. A multivariate analysis of mortality at 90 days was performed using variables that are found to exhibit a significant difference in the univariate analysis in addition to variables with a significant difference between the groups on admission (WBC and KL-6). All statistical analyses were performed using the EZR Software package (Saitama Medical Center, Jichi Medical University, Saitama, Japan), ${ }^{16}$ a graphical user interface for R (The R Formulation for Statistical Computing Version 3.0.3). Statistical significance was defined as a $P$-value of $<0.05$.

\section{Results Study population}

Sixteen patients with AE-IPF and six patients with AE-NSIP were enrolled in this study. Six patients with AE-IPF were diagnosed based on the presence of usual interstitial pneumonia pattern on a surgical biopsy. The remaining ten patients 
with AE-IPF were diagnosed based on the findings of chest HRCT, excluding other differential diagnoses. Six patients with AE-NSIP were diagnosed based on the findings of HRCT, excluding other differential diagnoses. As shown in Figure 1, eleven patients with AE-IPF/NSIP were administered rhTM (rhTM group), and the other eleven patients with AE-IPF/ NSIP were not administered rhTM (non-rhTM group). The baseline values in the two groups (rhTM group and non-rhTM group) are shown in Table 1 . There were no significant differences between the two groups in terms of age, sex, clinical diagnosis of IPF/NSIP, administration of prednisolone or immunosuppressants prior to $\mathrm{AE}$, physical examination findings, sequential organ failure assessment score, acute physiology and chronic health evaluation II score, and $\mathrm{PaO}_{2} /$ $\mathrm{F}_{\mathrm{I}} \mathrm{O}_{2}$. The WBC and $\mathrm{KL}-6$ values were significantly higher in the rhTM group than those in the non-rhTM group $(P=0.047$ and $P=0.033$, respectively). The other laboratory data did not show any significant differences between the two groups.

Therapeutic interventions, outcomes, and causes of death are shown in Table 2. There were no significant differences in the therapeutic interventions between the two groups. A total of eight patients (six patients in the rhTM group and two patients in the non-rhTM group, $P=0.20$ ) underwent BAL using bronchoscopy. Lower respiratory tract infections were excluded based on the results of culture examinations of BAL fluid and/or sputum. Furthermore, we examined urinary antigens for S. pneumonia and L. pneumophilia serotype 1, antigens for influenza A and B viruses using pharyngeal swabs, antigenemia for cytomegalovirus, and serum antigens for Aspergillus. There were no patients with suggested infection.

\section{Effect of rhTM on mortality}

The mortality rate at 30 days after treatment was not significantly different between the rhTM and non-rhTM groups ( $18 \%$ vs $54 \%, P=0.18)$. In contrast, the mortality at 90 days after treatment was significantly lower in the rhTM group than in the non-rhTM group ( $36 \%$ vs $90 \%, P=0.023$ ). The cause of death included respiratory failure in ten patients in the non-rhTM group, whereas three of four patients died due to respiratory failure and one patient died due to drug-induced hepatic failure and renal failure in the rhTM group. The survival curves for the two groups determined according to the Kaplan-Meier analysis are shown in Figure 2. The median survival time (MST) was 14 days in the non-rhTM group.

\section{Effects of rhTM on the clinical data}

The CRP, $\mathrm{LDH}, \mathrm{PaO}_{2} / \mathrm{F}_{\mathrm{I}} \mathrm{O}_{2}$, and FDP values were compared between the two groups on the first day of admission (day 1) and on day 8 (Figure 3 ). The levels of CRP, LDH, and FDP were significantly decreased in the rhTM group compared to those observed in the non-rhTM group. Although we also compared the laboratory data obtained on day 3 , we were

Table I Baseline characteristics of the patients on admission

\begin{tabular}{|c|c|c|c|}
\hline & $\operatorname{rhTM}$ group $(n=I I)$ & Non-rhTM group $(n=I I)$ & $P$-value \\
\hline Age (years) & $68.9 \pm 7.3$ & $73.1 \pm 11.3$ & $0.15^{\#}$ \\
\hline Sex, male/female (n) & $10 / 1$ & $9 / 2$ & $1.0 *$ \\
\hline Clinical diagnosis (IPF/NSIP) (n) & $9 / 2$ & $7 / 4$ & $0.63^{*}$ \\
\hline Corticosteroid before admission, n (\%) & $3(27)$ & $2(18)$ & $1.0 *$ \\
\hline Immunosuppressant before admission, n (\%) & $0(0)$ & I (9) & $1.0 *$ \\
\hline SOFA score & $3.3 \pm 0.8$ & $3.1 \pm 1.7$ & $0.70^{\#}$ \\
\hline APACHE II score & $9.8 \pm 4.9$ & $8.3 \pm 2.7$ & $0.5 I^{\#}$ \\
\hline $\mathrm{PaO}_{2} / \mathrm{F}_{1} \mathrm{O}_{2}(\mathrm{mmHg})$ & $198 \pm 62$ & $234 \pm 126$ & $0.7 I^{\#}$ \\
\hline $\mathrm{WBC}(\mathrm{I} / \mu \mathrm{L})$ & $|4,590 \pm 6,03|$ & $9,518 \pm 2,835$ & $0.047^{\#}$ \\
\hline LDH (IU/L) & $430 \pm 148$ & $419 \pm 150$ & $0.89^{\#}$ \\
\hline CRP $(\mathrm{mg} / \mathrm{dL})$ & $6.8 \pm 5.8$ & $11.3 \pm 7.3$ & $0.12^{\#}$ \\
\hline $\mathrm{BNP}(\mathrm{pg} / \mathrm{mL})$ & $91 \pm 106$ & $223 \pm 268$ & $0.19^{\#}$ \\
\hline KL-6 (U/L) & $2,018 \pm 780$ & $\mathrm{I}, 489 \pm 1,385$ & $0.033^{\#}$ \\
\hline SP-D (ng/mL) & $759 \pm 638$ & $338 \pm 338$ & $0.16^{\#}$ \\
\hline $\mathrm{FDP}(\mu \mathrm{g} / \mathrm{mL})$ & $8.6 \pm 4.7$ & $8.4 \pm 5.6$ & $0.59^{\#}$ \\
\hline D-dimer $(\mathrm{mg} / \mathrm{mL})$ & $4.4 \pm 3.7$ & $3.3 \pm 4.9$ & $0.09^{\#}$ \\
\hline TAT (ng/mL) & $9.1 \pm 11.0$ & $14.8 \pm 22.7$ & $0.70^{\#}$ \\
\hline PIC (ng/mL) & $1.4 \pm 0.4$ & $1.8 \pm 0.7$ & $0.22^{\#}$ \\
\hline
\end{tabular}

Notes: Data are expressed as mean \pm standard deviation. \#Mann-Whitney U-test and *Fisher's exact test.

Abbreviations: rhTM, recombinant human thrombomoduline; IPF, idiopathic pulmonary fibrosis; NSIP, nonspecific interstitial pneumonia; SOFA, sequential organ failure assessment; APACHE II, acute physiology and chronic health evaluation II; $\mathrm{PaO}_{2}$, oxygen partial pressure; WBC, white blood cell; LDH, lactate dehydrogenase; CRP, C-reactive protein; BNP, brain natriuretic peptide; KL-6, Krebs von den Lungen-6; SP-D, surfactant protein-D; FDP, fibrinogen degradation products; TAT, thrombin-antithrombin; PIC, plasmin-alpha 2-plasmin inhibitor complex; $\mathrm{F}_{1} \mathrm{O}_{2}$, fraction of inspired oxygen. 
Table 2 Therapeutic interventions, outcomes, and cause of death of the patients

\begin{tabular}{|c|c|c|c|}
\hline & $\operatorname{rhTM}$ group $(n=I I)$ & Non-rhTM group $(n=I I)$ & $P$-value \\
\hline BAL available, $\mathrm{n}(\%)$ & $6(54)$ & $2(18)$ & $0.18^{*}$ \\
\hline Neutrophils in BAL (\%) & $36.0 \pm 34.2$ & $66.0 \pm 35.0$ & $0.22^{\#}$ \\
\hline Lymphocytes in BAL (\%) & $13.5 \pm 15.7$ & $7.0 \pm 5.4$ & $0.66^{\#}$ \\
\hline Corticosteroid pulse therapy, n (\%) & II (100) & $10(90)$ & $1.0 *$ \\
\hline Immunosuppressants other than corticosteroid, n (\%) & $9(8 \mathrm{I})$ & $7(63)$ & $0.63^{*}$ \\
\hline Nasal high flow, n (\%) & I (9) & $2(18)$ & $1.0 *$ \\
\hline Mechanical ventilation, $\mathrm{n}(\%)$ & $6(54)$ & $5(45)$ & $1.0^{*}$ \\
\hline NIPPV, n (\%) & $6(54)$ & $5(45)$ & $1.0^{*}$ \\
\hline IMV, n (\%) & $0(0)$ & $0(0)$ & $1.0^{*}$ \\
\hline Broad spectrum antibiotics therapy, n (\%) & II $(100)$ & II $(100)$ & $1.0 *$ \\
\hline \multicolumn{4}{|l|}{ Death } \\
\hline 30 days death, $\mathrm{n}(\%)$ & $2(18)$ & $6(54)$ & $0.18^{*}$ \\
\hline 90 days death, $\mathrm{n}(\%)$ & $4(36)$ & $10(90)$ & $0.023 *$ \\
\hline \multicolumn{4}{|l|}{ Cause of death } \\
\hline Respiratory failure, n (\%) & $3(75)$ & $10(100)$ & $0.28 *$ \\
\hline Drug-induced hepatic and renal failure, $n(\%)$ & $\mathrm{I}(25)$ & $0(0)$ & $0.28 *$ \\
\hline
\end{tabular}

Notes: Data are expressed as mean \pm standard deviation. \#Mann-Whitney U-test and *Fisher's exact test.

Abbreviations: rhTM, recombinant human thrombomoduline; BAL, bronchoalveolar lavage; NIPPV, noninvasive positive pressure ventilation; IMV, invasive mechanical ventilation.

unable to confirm a tendency toward improvement in the rhTM group.

\section{Prognostic factors}

The univariate analysis revealed rhTM administration (HR $0.21,95 \%$ confidence interval $[\mathrm{CI}] 0.06-0.77, P=0.013$ ) as predictors of mortality at 90 days (Table 3 ). Meanwhile, the multivariate analysis identified rhTM administration (HR $0.17,95 \%$ CI $0.034-0.88, P=0.035$ ) as an independent predictor of mortality at 90 days (Table 4 ).

\section{Adverse events}

One patient in the rhTM group died due to hepatic and renal failure 31 days after admission. Due to the interaction of warfarin administered to treat atrial fibrillation, it was difficult to control the patient's blood cyclosporine concentration. Therefore, we suspected that the adverse event was due to the high concentration of cyclosporine. The patient developed hepatic and renal failure 24 days after the last administration of rhTM, and we thus consider no relationship between the adverse event and rhTM in this case. There were no other adverse events in this study.

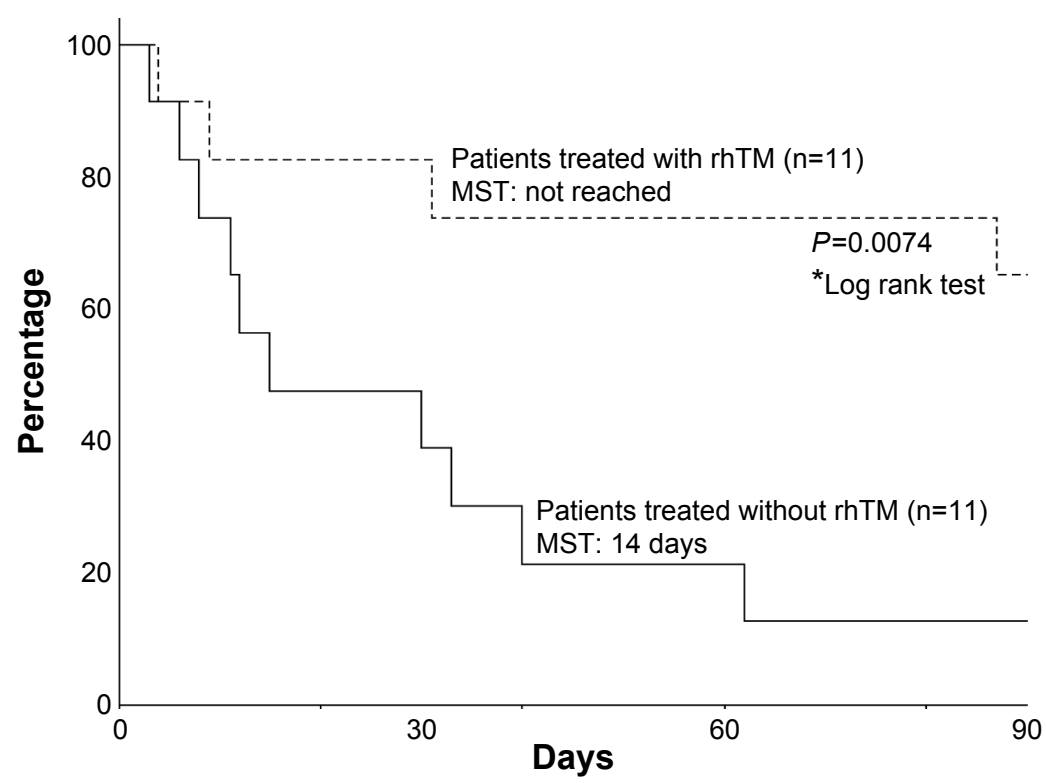

Figure 2 The survival curve of eleven patients with acute exacerbation who were treated with rhTM and eleven patients with acute exacerbation who were treated without rhTM.

Abbreviations: rhTM, recombinant human thrombomoduline; MST, median survival time. 

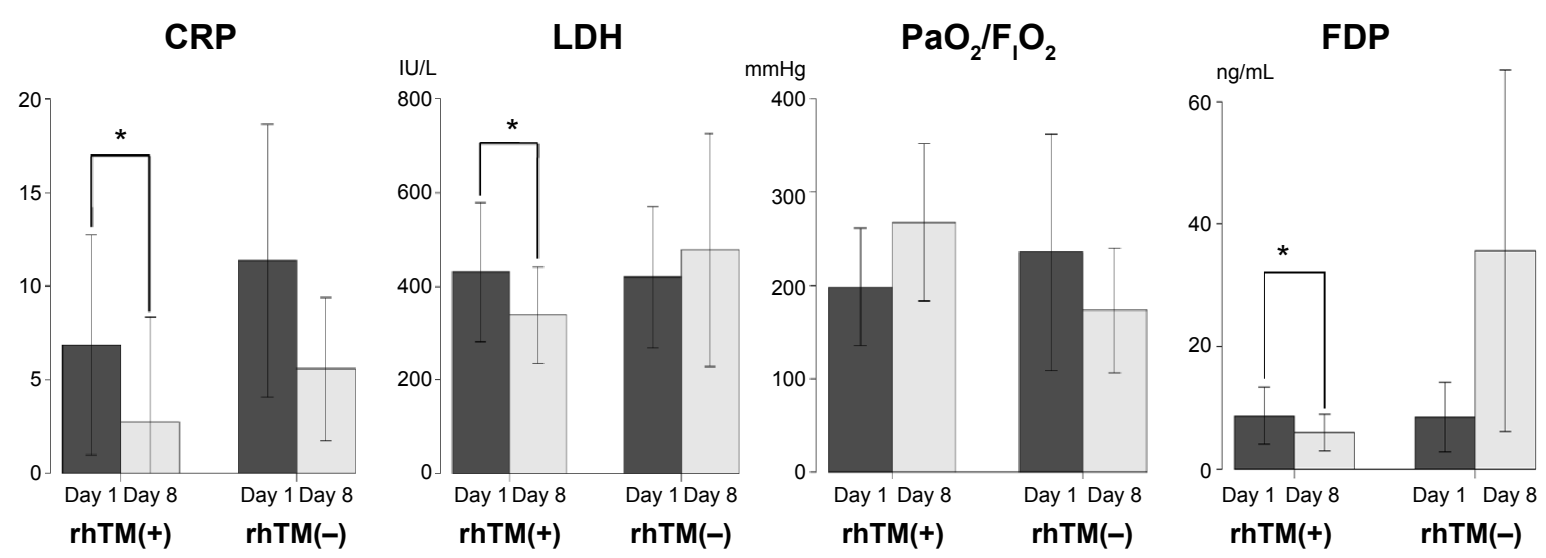

Figure 3 The serial changes in the clinical data between patients with AE-IPF/NSIP treated with rhTM (rhTM group) and without rhTM (non-rhTM group). Notes: Serum CRP, serum LDH, and plasma FDP were decreased significantly in rhTM group. Wilcoxon's signed rank test. $* P<0.05$.

Abbreviations: AE, acute exacerbation; IPF, idiopathic pulmonary fibrosis; NSIP, nonspecific interstitial pneumonia; rhTM, recombinant human thrombomoduline; CRP, C-reactive protein; $\mathrm{LDH}$, lactate dehydrogenase; FDP, fibrinogen degradation products; $\mathrm{PaO}_{2}$, oxygen partial pressure; $\mathrm{F}_{1} \mathrm{O}_{2}$, fraction of inspired oxygen.

\section{Discussion}

This prospective study showed that intravenous rhTM treatment has the potential to improve outcomes in patients with AE-IPF/NSIP. In particular, the univariate and multivariate analyses revealed the efficacy of rhTM. We propose that the discrepancy in the survival rates between the two groups was due to the administration of rhTM, as the therapeutic strategy and initial data, other than the WBC and KL-6

Table 3 Univariate analysis of survival

\begin{tabular}{|c|c|c|c|}
\hline & Hazard ratio & $95 \% \mathrm{Cl}$ & $P$-value \\
\hline Age (years) & 1.04 & $0.97-1.11$ & 0.23 \\
\hline Male sex & 1.12 & $0.25-5.03$ & 0.87 \\
\hline SOFA score & 1.07 & $0.65-1.77$ & 0.76 \\
\hline APACHE II score & 1.05 & $0.91-1.21$ & 0.48 \\
\hline $\mathrm{PaO}_{2} / \mathrm{F}_{1} \mathrm{O}_{2}(\mathrm{mmHg})$ & 1.00 & $0.99-1.00$ & 0.69 \\
\hline WBC $(I / \mu L)$ & 1.00 & $0.99-1.00$ & 0.96 \\
\hline LDH (IU/L) & 1.00 & $0.99-1.00$ & 0.67 \\
\hline CRP $(\mathrm{mg} / \mathrm{dL})$ & 1.04 & $0.97-1.11$ & 0.25 \\
\hline $\mathrm{BNP}(\mathrm{pg} / \mathrm{mL})$ & 1.00 & $1.00-1.00$ & 0.051 \\
\hline KL-6 (U/L) & 0.99 & $0.99-1.00$ & 0.15 \\
\hline SP-D (ng/mL) & 0.99 & $0.99-1.00$ & 0.052 \\
\hline $\mathrm{FDP}(\mu \mathrm{g} / \mathrm{mL})$ & 0.98 & $0.85-1.12$ & 0.78 \\
\hline D-dimer $(\mathrm{mg} / \mathrm{mL})$ & 0.99 & $0.85-1.15$ & 0.92 \\
\hline TAT $(\mathrm{ng} / \mathrm{mL})$ & 0.98 & $0.95-1.02$ & 0.51 \\
\hline $\mathrm{PIC}(\mathrm{ng} / \mathrm{mL})$ & 0.97 & $0.38-2.49$ & 0.96 \\
\hline BAL available (\%) & 0.73 & $0.22-2.35$ & 0.60 \\
\hline Neutrophils in BAL (\%) & 1.78 & $0.48-6.62$ & 0.38 \\
\hline Lymphocytes in BAL (\%) & 0.75 & $0.56-1.01$ & 0.060 \\
\hline rhTM administration & 0.21 & $0.06-0.77$ & $0.013^{*}$ \\
\hline
\end{tabular}

Note: *Cox proportional hazards' regression models.

Abbreviations: $\mathrm{Cl}$, confidence interval; SOFA, sequential organ failure assessment; APACHE II, acute physiology and chronic health evaluation II; $\mathrm{PaO}_{2}$, oxygen partial pressure; WBC, white blood cell; $L D H$, lactate dehydrogenase; CRP, C-reactive protein; BNP, brain natriuretic peptide; KL-6, Krebs von den Lungen-6; SP-D, surfactant protein-D; FDP, fibrinogen degradation products; TAT, thrombin-antithrombin; PIC, plasmin-alpha 2-plasmin inhibitor complex; BAL, bronchoalveolar lavage; rhTM, recombinant human thrombomodulin; $\mathrm{F}_{1} \mathrm{O}_{2}$, fraction of inspired oxygen. levels, were not significantly different between the two groups.

Kubo et al reported that disorders of coagulation and fibrinolysis are important components of AE-IPF and that anticoagulant therapy for AE-IPF is efficient. ${ }^{17}$ However, Noth et al reported that treatment with warfarin in patients with progressive IPF was found to be associated with an increased risk of mortality in a double-blinded, randomized, placebo-controlled trial. ${ }^{18}$

The rhTM is an intravenous therapeutic agent against acute DIC in Japan and has effects to improve the burst of coagulation systems. Recently, there have been reports indicating that the levels of serum coagulation factors are higher in patients with AE-IPF than in patients with IPF..$^{19,20}$ We suppose that these data show pathologically localized coagulation disturbance in the parenchymal lung lesions of patients with AE-IPF/NSIP. Tsushima et al also reported that the administration of rhTM improves activated coagulation disturbances and that the mortality rate at 28 days is significantly lower in AE-IPF patients treated with rhTM than in those treated without rhTM. ${ }^{19}$ In this study, the CRP, $\mathrm{LDH}$, and FDP values on day 8 decreased significantly in the rhTM group. This finding suggests that the administration

Table 4 Multivariate analysis of survival

\begin{tabular}{llll}
\hline & Hazard ratio & $\mathbf{9 5 \%} \mathbf{C l}$ & P-value \\
\hline WBC $(\mathrm{I} / \mu \mathrm{L})$ & 1.00 & $1.00-1.00$ & 0.062 \\
KL-6 $(\mathrm{U} / \mathrm{L})$ & 0.99 & $0.99-1.00$ & 0.17 \\
BNP $(\mathrm{pg} / \mathrm{mL})$ & 1.00 & $0.99-1.00$ & 0.10 \\
rhTM administration & 0.17 & $0.034-0.88$ & $0.035^{*}$ \\
\hline
\end{tabular}

Note: *Cox proportional hazards' regression models.

Abbreviations: $\mathrm{Cl}$, confidence interval; WBC, white blood cell; KL-6, Krebs von den Lungen-6; BNP, brain natriuretic peptide; rhTM, recombinant human thrombomodulin. 
of rhTM may improve disturbances of coagulation and a hyperinflammatory state. Therefore, rhTM administration is useful for AE status in IPF/NSIP-patients with disturbances of coagulation system.

Thrombomodulin plays an important role in regulating both coagulation and inflammation. 1) Thrombomodulin binds to thrombin and inhibits activity of thrombin. 2) The protein C, which is activated by the thrombin-thrombomodulin complex, inhibits coagulant activity. 3) The activated protein $C$ has an anti-inflammatory effect by downregulating the expression of inflammatory cytokines, such as tumor necrosis factor-alpha. ${ }^{21,22}$ 4) Thrombomodulin has another mechanism underlying the anti-inflammatory effects, ie, the N-terminal lectin-like domain of thrombomodulin inactivates sequesters high-mobility group box-1 protein (HMGB-1), which is released from necrotic cells and subsequently causes cell damage. ${ }^{23}$ Deng et al reported that HMGB-1 activates alveolar macrophages to produce proinflammatory cytokines and induce acute lung injury. ${ }^{24}$ In addition, a previous report showed that the serum HMGB-1 levels are significantly lower in survivors than in nonsurvivors. ${ }^{19}$ Therefore, the anti-inflammatory activity of rhTM is considered to be an important factor for the mortality of AE-IPF. In this study, the serum CRP levels improved more significantly in the rhTM group than in the non-rhTM group (Figure 3 ).

In the non-rhTM group, the MST was 14 days. This is shorter than that noted in the previous reports. ${ }^{3,5}$ The official ATS/ERS/JRS/ALAT statement recommends that the majority of patients with respiratory failure due to IPF should not receive mechanical ventilation. ${ }^{14}$ Therefore, in this study, no patients were treated using invasive mechanical ventilation. In the patients in whom it was not possible to maintain the blood concentration of oxygen with noninvasive ventilation, we primarily offered treatment to relieve their discomfort and dyspnea with drugs such as morphine. Morphine also has an effect in inducing respiratory suppression. For this reason, the MST was shorter in the non-rhTM group than in the previous reports.

This study is associated with several limitations. First, this study was a single-center, nonrandomized prospective study. Therefore, the background factors of the two groups were slightly different. In particular, the WBC and KL-6 levels on admission were significantly higher in the rhTM group than in the non-rhTM group. We suppose that these differences on admission did not influence the prognosis of the two groups, as high WBC and KL-6 levels are not thought to be good prognostic factors in general. We therefore conducted a multivariate analysis including different factors identified in the univariate analysis as well as the WBC and KL-6 levels. Second, the number of patients was too small. For this reason, some differences between the two groups at the time of hospitalization were observed, although not significant. For instance, the age of the patients in the rhTM group was less than those in the non-rhTM group (68.9 \pm 7.3 years vs $73.1 \pm 11.3$ years, respectively, Table 1). Third, we were unable to confirm the existence of microvascular thrombus formation in the lungs of the patients with AE-IPF/NSIP pathologically. It is necessary to clarify the effects of rhTM on the pathophysiology of AE-IPF/NSIP. Fourth, since corticosteroids were administered in all cases and the levels of inflammatory markers other than CRP (eg, HMGB-1) were not measured, we were unable to sufficiently evaluate the anti-inflammatory effects of rhTM.

\section{Conclusion}

The administration of rhTM is associated with reductions in mortality in patients with AE-IPF/NSIP. In order to confirm this finding, a large-scale, prospective, randomized, doubleblinded study is needed.

\section{Acknowledgments}

We thank Ikuko Sakamoto, our clinical assistant, for keeping the patient records. The authors received no funding or financial support from any industry.

\section{Author contributions}

All authors contributed to the conceptual design of the survey. $\mathrm{M}$ Abe and K Tsushima performed the statistical analysis. All authors took part in either drafting the article or revising it critically for important intellectual content. All authors read and approved the final manuscript.

\section{Disclosure}

The authors report no conflicts of interest in this work.

\section{References}

1. Kondoh K, Taniguchi H, Kawabata Y, Yokoi T, Suzuki K, Takagi K. Acute exacerbation in idiopathic pulmonary fibrosis. Chest. 1993;103: 1808-1812.

2. Song JW, Hong SB, Lim CM, Koh Y, Kim DS. Acute exacerbation of idiopathic pulmonary fibrosis: incidence, risk factors and outcome. Eur Respir J. 2011;37:356-363.

3. Agarwal R, Jindal SK. Acute exacerbation of idiopathic pulmonary fibrosis: a systematic review. Eur J Intern Med. 2008;19:227-235.

4. Park IN, Kim DS, Shim TS, et al. Acute exacerbation of interstitial pneumonia other than idiopathic pulmonary fibrosis. Chest. 2007;132: 214-220

5. Usui Y, Kaga A, Sakai F, et al. A cohort study of mortality predictors in patients with acute exacerbation of chronic fibrosing interstitial pneumonia. BMJ Open. 2013;3:e002971. 
6. Homma S, Sakamoto S, Kawabata M, et al. Cyclosporin treatment in steroid-resistant and acutely exacerbated interstitial pneumonia. Intern Med. 2005;44:1144-1150.

7. Inase N, Sawada M, Ohtani Y, et al. Cyclosporin A followed by the treatment of acute exacerbation of idiopathic pulmonary fibrosis with corticosteroid. Intern Med. 2003;42:565-570.

8. Sakamoto S, Homma S, Miyamoto A, Kurosaki A, Fujii T, Yoshimura K. Cyclosporin A in the treatment of acute exacerbation of idiopathic pulmonary fibrosis. Intern Med. 2010;49:109-115.

9. Van de Wouwer M, Collen D, Conway EM. Thrombomodulin-protein C-EPCR system: integrated to regulate coagulation and inflammation. Arterioscler Thromb Vasc Biol. 2004;24:1374-1383.

10. Macias WL, Yan SB, Williams MD, et al. New insights into the protein $\mathrm{C}$ pathway: potential implications for the biological activities of drotrecogin alfa (activated). Crit Care. 2005;9(suppl 4): S38-S45.

11. Ogawa Y, Yamakawa K, Ogura H, et al. Recombinant human soluble thrombomodulin improves mortality and respiratory dysfunction in patients with severe sepsis. J Trauma Acute Care Surg. 2012;72: $1150-1157$.

12. Gando S, Iba T, Eguchi Y, et al. A multicenter, prospective validation of disseminated intravascular coagulation diagnostic criteria for critically ill patients: comparing current criteria. Crit Care Med. 2006;34: 625-631.

13. Raghu G, Collard HR, Egan JJ, et al. An official ATS/ERS/JRS/ALAT statement: idiopathic pulmonary fibrosis: evidence-based guidelines for diagnosis and management. Am J Respir Crit Care Med. 2011; 183:788-824.

14. Palmucci S, Roccasalva F, Puglisi S, et al. Clinical and radiological features of idiopathic interstitial pneumonias (IIPs): a pictorial review. Insights Imaging. 2014;5:347-364.
15. Collard HR, Moore BB, Flaherty KR, et al. Acute exacerbations of idiopathic pulmonary fibrosis. Am J Respir Crit Care Med. 2007;176: 636-643.

16. Kanda Y. Investigation of the freely available easy-to-use software 'EZR' for medical statistics. Bone Marrow Transplant. 2013;48:452-458.

17. Kubo H, Nakayama K, Yanai M, et al. Anticoagulant therapy for idiopathic pulmonary fibrosis. Chest. 2005;128:1475-1482.

18. Noth I, Anstrom KJ, Calvert SB, et al. A placebo-controlled randomized trial of warfarin in idiopathic pulmonary fibrosis. Am J Respir Crit Care Med. 2012;186:88-95.

19. Tsushima K, Yamaguchi K, Kono Y, et al. Thrombomodulin for acute exacerbations of idiopathic pulmonary fibrosis: a proof concept study. Pulm Pharmacol Ther. 2014;29:233-240.

20. Bargagli E, Madioni C, Bianchi N, Refini RM, Cappelli R, Rottoli P. Serum analysis of coagulation factors in IPF and NSIP. Inflammation. 2014;37:10-16.

21. Murakami K, Okajima K, Uchiba M, et al. Activated protein C prevents LPS-induced pulmonary vascular injury by inhibiting cytokine production. Am J Physiol. 1997;L272:197-202.

22. Toltl LJ, Beaudin S, Liaw PC. Activated protein C up-regulates IL-10 and inhibits tissue factor in blood monocytes. J Immunol. 2008;181: 2165-2173.

23. Abeyama K, Stern DM, Ito Y, et al. The Nterminal domain of thrombomodulin sequesters high-mobility group-B1 protein, a novel antiinflammatory mechanism. J Clin Invest. 2005;115:1267-1274.

24. Deng Y, Yang Z, Gao Y, et al. Toll-like receptor 4 mediates acute lung injury induced by high mobility group box-1. PLoS One. 2013;17: e64375.
Drug Design, Development and Therapy

\section{Publish your work in this journal}

Drug Design, Development and Therapy is an international, peerreviewed open-access journal that spans the spectrum of drug design and development through to clinical applications. Clinical outcomes, patient safety, and programs for the development and effective, safe, and sustained use of medicines are a feature of the journal, which

\section{Dovepress}

has also been accepted for indexing on PubMed Central. The manuscript management system is completely online and includes a very quick and fair peer-review system, which is all easy to use. Visit http://www.dovepress.com/testimonials.php to read real quotes from published authors. 